\title{
Preface to the Enlarged Edition
}

Why a new edition? Following what at the time appeared to be a climactic Meeting of Parties in London in 1990 that adopted substantially stronger controls over ozone-depleting substances, the scientific evidence took a dramatic and unexpected turn for the worse. In the six years since Ozone Diplomacy appeared, the Montreal Protocol has undergone major transformations. Existing controls were significantly strengthened, and, after the often-contentious debates, many new chemicals were added to the lists of controlled substances. A completely new type of financial mechanism was created to assist developing countries in obtaining new technologies and phasing out environmentally damaging substances and processes. The protocol's institutional structure has matured to meet unanticipated issues in implementation, and has served as a model for many subsequent environmental accords, including the Framework Convention on Climate Change, the Convention on Biological Diversity, the restructured Global Environment Facility, and the Convention to Combat Desertification. Governments, in unique and unforeseen partnerships with private industry and environmental organizations, have experimented with a variety of market-oriented and other policies to effect a successful technological transformation from the once-ubiquitous CFCs and their sister chemicals.

During these years the Montreal Protocol has also weathered a wave of revisionism that sought, for antiregulatory ideological reasons, to discredit the ozone science; legislation was actually introduced in the United States to roll back controls on ozone-depleting substances. The protocol has contended with the threat of black-market exports of CFCs and other attempts to evade the treaty. Innovative procedures were developed to assist several countries, among them a major producing nation, Russia, to overcome an unanticipated, serious situation of noncompliance with control provisions following the turmoil of the breakup of the Soviet Union and the overthrow of Communist regimes in eastern Europe.

Barring unforeseen events, the tenth anniversary of the signing of the Montreal Protocol represents a culmination. Although the work of pro- 
tecting the ozone layer is not finished, the major challenges have been successfully addressed. The industrialized countries have either phased out, or are in the process of phasing out, all the serious ozone-depleting substances, as well as the less-damaging transitional substances (HCFCs). The developing countries have also accepted phaseout schedules and appear to have turned the corner on their hitherto-increasing usage of ozone-depleting substances as a great wave of new technologies is being diffused throughout the world. The protocol's noncompliance procedures have demonstrated their resilience and effectiveness.

There have been six Meetings of Parties to the Montreal Protocol since London, as well as scores of other negotiating sessions; expert panels on science, technology, and economics; and committee meetings dealing with financial aid, implementation, and noncompliance issues. These years have produced new mountains of primary source material: documentation of negotiations, technical options studies, reports on financial aid needs and issues, scientific treatises, technological research, analyses of national programs and progress. There has also been much secondary material on the Montreal Protocol written by academics, journalists, and others-not all of it accurate. There have been many partial studies, some quite excellent, but there remains a need for an overview of the entire experience in protecting the ozone layer.

This new edition attempts to fill this gap. The first edition of ozone Diplomacy was written for, and has been used by, both general readers and students in many universities in the United States and other countries. Because of the unusual success of the protocol negotiations, I felt it would be useful to complete the ozone story from the perspective of a practicing negotiator. My subsequent experience as special adviser to the secretaries-general during the negotiations leading up to both the 1992 UN Conference on Environment and Development/Earth Summit (UNCED) in Rio de Janeiro and the 1994 International Conference on Population and Development in Cairo provided me with an enriched appreciation of the complexities of this new generation of multilateral negotiations on global themes.

This had led to five totally new chapters (14 through 18) covering developments since London. The concluding chapter 19 contains expanded insights on the significance of, and lessons learned from, the ozone experience. In addition, there is a new analysis of the related ongoing negotiations on the Framework Convention on Climate Change, in which I first participated as representative of the UNCED secretarygeneral. 
In sum, there is a new story to be told, and I believe it is a fascinating and instructive one. Many people have aided me in telling this story. I am particularly grateful to the World Wildlife Fund (President Kathryn Fuller, Senior Vice President James Leape, and Vice President Richard Mott) and to the Wissenschaftszentrum Berlin (President Friedhelm Neidhardt and Professor Udo E. Simonis) for providing institutional support and encouragement in what proved to be a bigger project than originally anticipated, and to Frank Biermann of Berlin for his invaluable research, especially on the financial mechanism. I very much appreciate the insights and assistance of Ambassador Winfried Lang of Austria; Eileen Claussen and Rafe Pomerance, who have ably led U.S. delegations to recent ozone negotiations, and U.S. officials Daniel Albritton, Stephen Andersen, Paul Horwitz, Bradford Johnson, and Steven Seidel; Rajendra Shende and the staff of UNEP's Industry and Environment Center; Elizabeth Cook, Hilary French, and Alan Miller of the private research community; David Stirpe of the Alliance for Responsible Atmospheric Policy; Tom Roper, former environment minister of Victoria, Australia; and Irene Federwisch, German Foundation for International Development. I also count myself very lucky (again) for the perceptive advice of Ann Hawthorne, senior editor at Harvard University Press. After all this help, the responsibility for any remaining shortcomings rests solely on me. 